\title{
SEVERE PERICARDIAL EFFUSION IN ERASMUS SYNDROME
}

Marcella Maria Soares Mello ${ }^{1, \star}$, Thales Henrique Viana Azevedo ${ }^{1}$, Leticia Neves Martins ${ }^{1}$, Izabella Soares Mello², Gustavo Lamego de Barros Costa ${ }^{1}$, Eduardo José do Rosário e Souza ${ }^{1}$

1.Santa Casa de Misericórdia Belo Horizonte, Belo Horizonte (MG), Brazil. 2.Faculdade de Saúde e Ecologia Humana, Vespasiano (MG), Brazil. *Corresponding author: marcellamsmello@gmail.com

\section{BACKGROUND}

Occupational exposure to silica dust is related to autoimmune diseases and individuals with silicosis are 28 times more at risk for developing systemic sclerosis (SSc). Pericardial involvement in SSc is well described in literature, but heart disease in silicosis, leading to pericardial effusion, is a rare condition.

\section{CASE REPORT}

A 72-year-old male patient, gold miner for more than 30 years in Minas Gerais, and former smoker was diagnosed with silicosis in 1996. In 2007, he developed skin thickening of hands and feet, Raynaud's phenomenon with ulcers in digital pulps and amputation of some distal phalanges, and positive ANA 1:640 centromeric pattern. He was diagnosed with systemic sclerosis with limited cutaneous form and start treatment with prednisone and azathioprine.

In 2015, he was diagnosed with mild pericardial effusion but he was asymptomatic. In 2020, the echocardiogram shows severe pericardial effusion, but without signs of cardiac tamponade. The patient was submitted to pericardiocentesis and biopsy, and $400 \mathrm{ml}$ of yellow citrus liquid was drained with negative propaedeutics for infectious etiologies. Histopathological study showed nonspecific findings. Absence of malignancy and investigation of negative silica in the sample. The patient was discharged using prednisone $20 \mathrm{mg} /$ day and colchicine $0.5 \mathrm{mg}$ twice a day.

\section{CONCLUSION}

A rare case of massive pericardial effusion in a patient with Erasmus syndrome has been reported. In this context, the etiological investigation involves the activity of systemic sclerosis per se, chronic inflammation of the pericardium due to the deposition of silica, tuberculosis and various neoplasms. In the present case, by exclusion, the defined cause was SS. 